\title{
The Efficacy and Safety of Apatinib in Advanced Synovial Sarcoma: A Case Series of Twenty-One Patients in One Single Institution
}

This article was published in the following Dove Press journal: Cancer Management and Research

\section{Yitian Wang* \\ Minxun Lu* \\ Yong Zhou \\ Sisi Zhou \\ Xinzhu Yu \\ Fan Tang \\ Yi Luo \\ Wenli Zhang \\ Hong Duan \\ Li Min \\ Chongqi Tu}

Department of Orthopedics, West China Hospital, Sichuan University, Chengdu 61004I, Sichuan, People's Republic of China

*These authors contributed equally to this work
Correspondence: Li Min

Department of Orthopedics, West China Hospital, Sichuan University, No. 37

Guoxuexiang, Chengdu 61004I, People's

Republic of China

Tel +86 I3980095430

$\mathrm{Fax}+8602885582944$

Email minlil204@scu.edu.cn
Background: Synovial sarcoma (SS) is a highly aggressive soft-tissue sarcoma (STS) with poor prognosis. Tyrosine kinase inhibitor (TKI) has shown a promising impact on advanced STS patients. This study aimed to evaluate the efficacy and safety of apatinib, an oral multiTKI, which especially inhibited vascular endothelial growth factor receptor, as second-line therapy for patients with advanced SS.

Patients and Methods: This retrospective analysis included 21 advanced SS patients, who had a poor response to anthracycline-based chemotherapy alone or combined with ifosfamide at least one cycle. All the patients received an apatinib containing regimen between May 2016 and October 2019 in our institution. Apatinib 500-750 mg (250 mg for patients younger than 10) was given daily. Tumor responses were assessed by response evaluation criteria in solid tumors. Survival analysis was performed by the Kaplan-Meier test, and a safety profile was recorded.

Results: The median follow-up was 15.2 months (95\% CI, 12.2-NE). Nine (42.9\%) patients had partial response (PR), and eight (38.1\%) had stable disease. The median progression-free survival (PFS) was 13.1 months (95\% CI, 6.7-NE). The 6- and 12-month PFS rates were $76.2 \%$ (95\% CI, 60.0-96.8) and 55.4\% (95\% CI, 37.3-82.3), respectively. Additionally, the median overall survival (OS) was 15.5 months (95\% CI, 10.7-NE). The 6- and 12-month OS rates were $81.0 \%(95 \% \mathrm{CI}, 65.8,99.6)$ and $64.9 \%(95 \% \mathrm{CI}, 46.9-90.0)$, respectively. Moreover, the objective response rate was $42.9 \%$ (9/21) for advanced SS patients. The disease control rate was $81.0 \%(17 / 21)$. For the nine patients with the best response of PR, the median duration of response was 7.7 months.

Conclusion: Apatinib was proved to be a potential second-line treatment option for advanced SS patients with chemo-resistance. Apatinib showed promising efficacy and acceptable safety profile in advanced SS, with considerable OS and particularly PFS. Indeed, further multicenter studies with a longer follow-up time are needed to fully determine the clinical application of apatinib in advanced SS.

Keywords: synovial sarcoma, apatinib, targeted therapy, efficacy, safety

\section{Introduction}

Synovial sarcoma (SS) is an aggressive malignancy of mesenchymal origin, accounting for approximately $8 \%$ to $10 \%$ of all soft-tissue sarcomas (STS). ${ }^{1-3} \mathrm{SS}$ is marked by the presence of a pathognomonic translocation between chromosomes $\mathrm{X}$ and $18, \mathrm{t}(\mathrm{X} ; 18)(\mathrm{p} 11.2 ; \mathrm{q} 11.2){ }^{4}$ and its histological characteristics can be identified including monophasic, biphasic, and poorly differentiated SS. ${ }^{4}$ Although SS frequently arises in the extremities, its histological feature is not related to synovial 
tissue. $^{5}$ As the common non-rhabdomyosarcoma STS in children and young adults, the peak incidence of SS is adolescents and adults younger than 30 years ${ }^{5,7}$ Notably, SS has a high metastatic potential (approximately 24\% of the patients at diagnosis) and a high locally recurrent rate (approximately 17\% of patients). ${ }^{8,9}$

In general, $\mathrm{SS}$ is a high-grade sarcoma with a poor prognosis. ${ }^{10}$ For local SS, the standard treatment was wide resection followed by radiation therapy in patients with high-risk disease (ie, deeply located tumor site, and tumor size $>5 \mathrm{~cm}) .{ }^{11}$ For advanced $\mathrm{SS}$, anthracycline-based chemotherapy alone or combined with ifosfamide was regarded as the conventional frontline strategy. ${ }^{12,13}$ However, controversy has still existed related to the most effective therapy regimen. ${ }^{2}$ Once disease progression or chemo-resistance happened, no appropriate systemic agent is targeting the histologic or genomic characteristics of SS. Therefore, recently, several clinical trials on different approved palliative options have been reported, such as trabectedin, ${ }^{14}$ pazopanib, ${ }^{15}$ and regorafenib. ${ }^{3}$

Angiogenesis and multikinase inhibitors were recognized as active agents for advanced non-adipocytic sarcomas. ${ }^{15,16}$ Although pazopanib and regorafenib were reported to significantly improve progression-free survival (PFS) compared with placebo in advanced SS patients, these treatment strategies did not improve the overall survival (OS). ${ }^{3,16,17}$ Therefore, alternative options are needed. Apatinib is an oral anti-angiogenesis tyrosine kinase inhibitor (TKI) highly and selectively inhibitor on vascular endothelial growth factor receptor (VEGFR)-2. ${ }^{18}$ Promising efficacy of apatinib was reported in advanced gastric cancer ${ }^{19}$ and metastatic STS. ${ }^{20}$

No prior case series have described the efficacy and safety of apatinib in advanced SS. We further retrospectively studied the clinical outcomes of apatinib in 21 patients with advanced SS who have been previously treated at the Department of Orthopaedics of the West China Hospital.

\section{Patients and Methods}

\section{Patients Eligibility}

We examined advanced SS patients who were treated between May 2016 and October 2019 in our institution. The inclusion criteria were as follows: 1) histologically confirmed diagnosis of advanced SS according to the World Health Organization Classification of Tumours; 2) availability of complete data at the time of treatment including at least three measurable lesions according to Response Evaluation Criteria in Solid Tumors (RECIST) version 1.1 ; 3) intolerance or failure to anthracyclinebased chemotherapy alone or combine with ifosfamide at least one cycle. This study was performed according to the principles embodied in the Declaration of Helsinki and the Institutional Review Board of Sichuan University West China Hospital. Written informed consent was obtained from all patients when they began treatment for apatinib. The study protocol followed all appropriate guidelines according to the Declaration of Helsinki.

\section{Treatment Methods}

Apatinib was orally administered at a dose of $750 \mathrm{mg}$ for adults and $250 \mathrm{mg}$ for children (less than 10 years of age) once a day for a 28-day cycle. In each cycle, one dose reduction (500-250 mg) was allowed for drug-related grade 3/4 adverse events (AEs). Treatment continued until disease progression or occurrence of unacceptable toxicities (grade 3/4 AEs) or patient refuel. Post-protocol treatment was discreetly managed by the patients and their physicians. The tumor response evaluation was based on computed tomographic or magnetic resonance imaging findings was performed every 2 months. Responses were assessed according to the RECIST $1.1 .^{21}$

\section{Statistical Analysis}

Standard descriptive and analytic methods were used to describe the patient population and their baseline characteristics. Overall survival (OS) was defined as the time from the initiation of apatinib treatment to the date of death or last follow-up. Progression-free-survival (PFS) was defined as the time from initiation of the apatinib treatment to the date of documented disease progression or death from any cause. And OS and PFS were calculated using the Kaplan-Meier product-limit method. Disease control rate (DCR) was defined as the percentage of patients achieving a complete response (CR), partial response $(\mathrm{PR})$ and stable disease (SD); objective response rate (ORR) was defined as the percentage of patients showing $\mathrm{CR}$ and PR. Duration of response (DOR) was defined as the length of time that the tumor continues to respond to treatment without progressive disease (PD). In addition, the $95 \%$ confidence interval (CI)s of the DCR, ORR, and DOR were calculated using an asymptotic normal approximation. A two-tailed $p<0.05$ was considered statistically significant. The statistical analysis was 
performed using SPSS version 23 software (SPSS Inc., Chicago, IL, USA).

\section{Results}

\section{Patient Characteristics}

Overall, 21 patients with metastatic or recurrent SS were treated with apatinib as at least a second-line chemotherapy. The baseline characteristic of the patients is summarized (Table 1). $47.6 \%$ (10) of the patients were male, and the median age was $31.5 \pm 14.0$ years (range $8-71$ ). The most common primary tumor sites were extremities (81.0\%). All patients had undergone at least one first-line chemotherapy including: anthracycline-based agent alone $(\mathrm{n}=11,52.4 \%)$ and anthracycline combined with ifosfamide $(n=10,47.6 \%)$. After first-line chemotherapy, 16

Table I Patient Characteristics

\begin{tabular}{|c|c|c|}
\hline Total & $\begin{array}{l}\text { Number of } \\
\text { Patients (n) }\end{array}$ & $\begin{array}{l}\text { Percentage } \\
\text { (\%) }\end{array}$ \\
\hline \multicolumn{3}{|l|}{ Sex } \\
\hline Male & 10 & 47.6 \\
\hline Female & 11 & 52.4 \\
\hline \multicolumn{3}{|l|}{ Age(years) } \\
\hline Median & 26.00 & - \\
\hline Range & $8-71$ & - \\
\hline \multicolumn{3}{|c|}{$\begin{array}{l}\text { Patients' status at the } \\
\text { administration of apatinib }\end{array}$} \\
\hline Local recurrence & 5 & 23.8 \\
\hline Metastasis & 15 & 71.4 \\
\hline Both & I & 4.8 \\
\hline \multicolumn{3}{|l|}{ Metastatic site } \\
\hline Lung & 14 & 66.7 \\
\hline Bone & 2 & 9.5 \\
\hline \multicolumn{3}{|l|}{ Number of previous } \\
\hline \multicolumn{3}{|l|}{ chemotherapy } \\
\hline \multicolumn{3}{|c|}{ regimens chemotherapies } \\
\hline I & 5 & 23.8 \\
\hline 2 & 11 & 52.4 \\
\hline$\geq 3$ & 5 & 23.8 \\
\hline \multicolumn{3}{|l|}{ ECOG PS } \\
\hline 0 & 1 & 4.8 \\
\hline 1 & 13 & 61.9 \\
\hline 2 & 5 & 23.8 \\
\hline 3 & 2 & 9.5 \\
\hline \multicolumn{3}{|l|}{ Primary tumor site } \\
\hline Extremities & 17 & 81.0 \\
\hline Trunk & 4 & 19.0 \\
\hline
\end{tabular}

patients had distant metastasis, and 5 patients got local recurrence.

\section{Efficacy}

Among the 21 evaluable cases (Table 2), none of the patients were lost to follow-up and four patients died of lung metastasis. The median follow-up was 15.2 months (95\% CI, 12.2-NE). Nine (42.9\%) of 21 patients had PR, and eight $(38.1 \%)$ had SD. We did notice dramatic tumor shrinkage (Figure 1). The median PFS was 13.1 months (95\% CI, 6.7-NE) (Figure 2). The 6- and 12-month PFS rates were $76.2 \%(95 \% \mathrm{CI}, 60.0-96.8)$ and $55.4 \%(95 \%$ CI, 37.3-82.3), respectively. Additionally, the median OS was 15.5 months $(95 \%$ CI, 10.7-NE) (Figure 3). The 6and 12-month OS rates were $81.0 \%(95 \% \mathrm{CI}, 65.8,99.6)$ and $64.9 \%$ (95\% CI, 46.9-90.0), respectively. Moreover, the ORR was $42.9 \%(9 / 21)$ for advanced SS patients. The DCR was $81.0 \%(17 / 21)$. For the nine patients with the best response of PR, the median DOR was 7.7 months.

\section{Safety and Toxicity}

The common grade $\geq 1$ non-hematological toxicities were hand-foot skin reaction $(\mathrm{n}=7,33.3 \%)$ and oral ulcers $(\mathrm{n}=$ $7,33.3 \%)$ and vomiting $(\mathrm{n}=6,28.6 \%)$. The only grade 4 reaction was pneumothorax treated by dose reduction. And one patient discontinued apatinib because of hand-foot skin reaction. Most adverse reactions were mild (grades 1/2) and easily controlled (Table 3). And all the AEs were causally related to apatinib. No deaths were related to the experimental treatment.

\section{Discussion}

Although SS is a relatively chemo-sensitive STS compared with adipocytic STS, ${ }^{12}$ the efficacy of neoadjuvant chemotherapy in advanced SS remains controversial. ${ }^{22}$ Various targeted regiments are used as second-line treatments after the failure of anthracycline-based chemotherapy, such as sorafenib, ${ }^{23}$ pazopanib, ${ }^{15,16,24-27}$ regorafenib ${ }^{3,17,28,29}$ and apatinib $^{20,30}$ (Table 4).

Among them, multitargeted TKIs can be effective in patients with metastatic or recurrent SS, which have different affinities against VEGFR $-1 / 2 / 3$, platelet-derived growth factor $-\alpha / \beta$, fibroblast growth factor receptor (FGFR) $-1 / 3$, stem cell factor (c-Kit) receptor, and implicated in oncogenesis (TIE2, RET, RAF). ${ }^{15,32}$ In previous studies, pazopanib and regorafenib had demonstrated acceptable antitumor activity with longer median PFS in metastatic or recurrent SS patients, compared with that of 


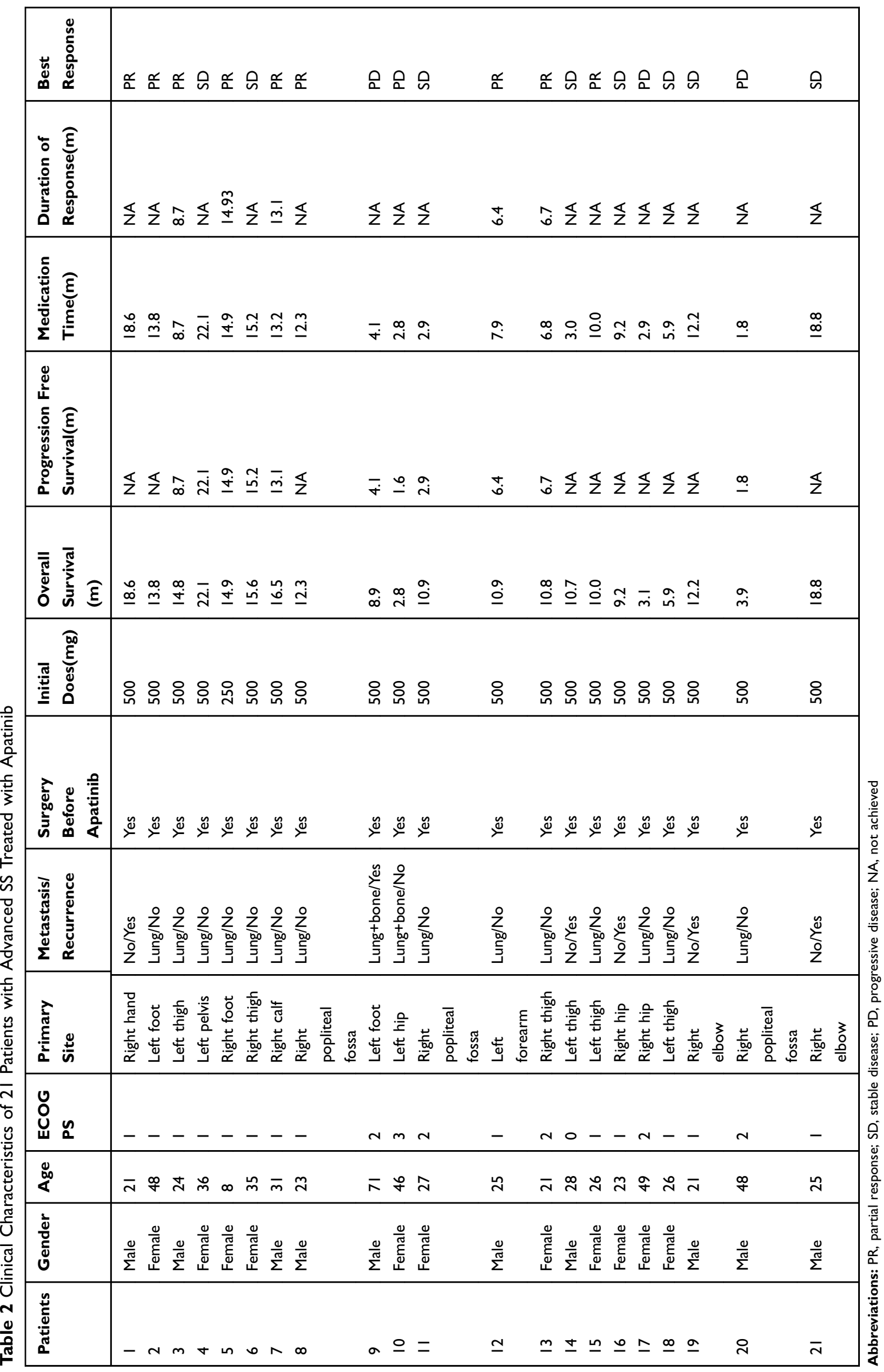




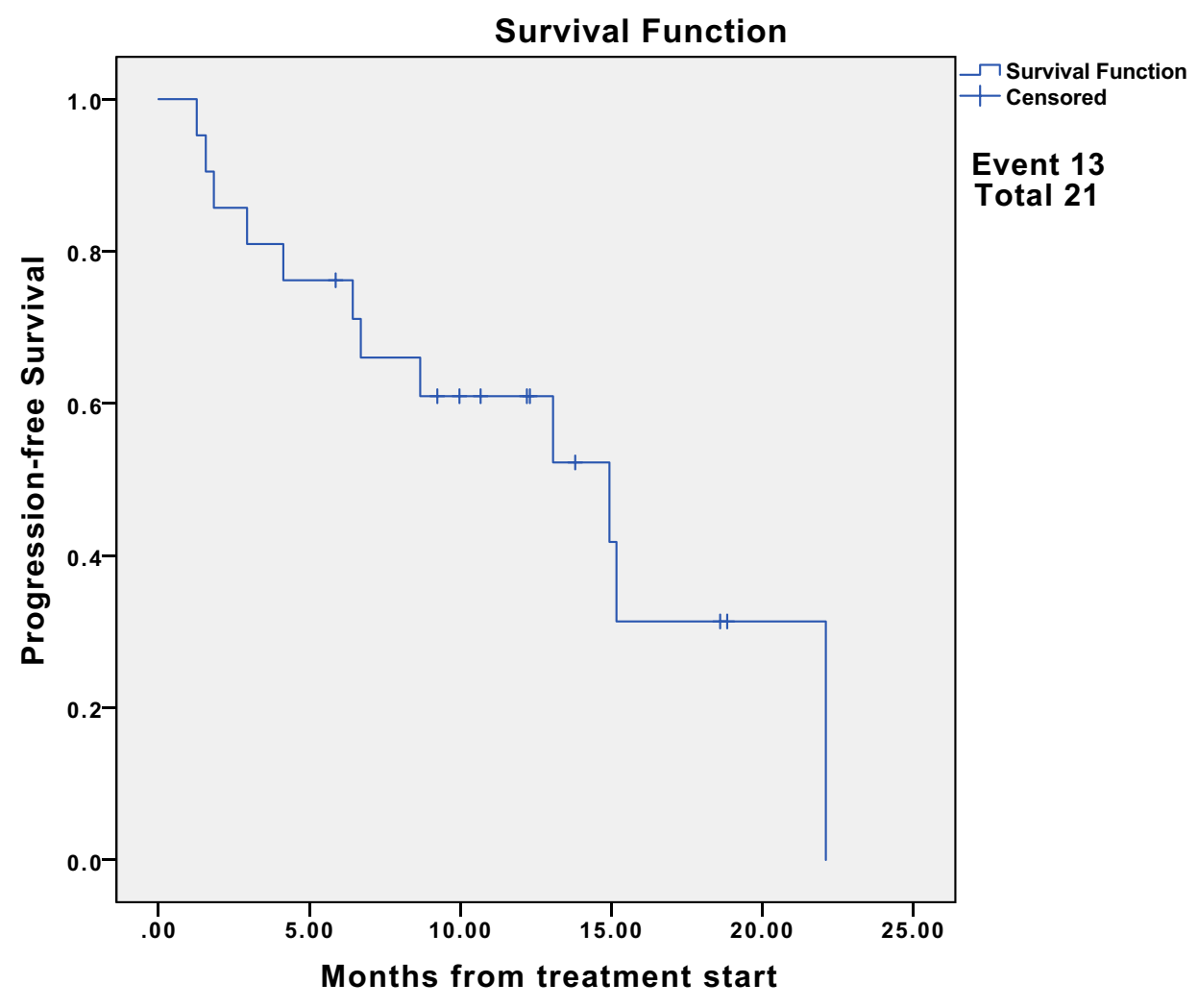

Figure I Maximum response to apatinib treatment.

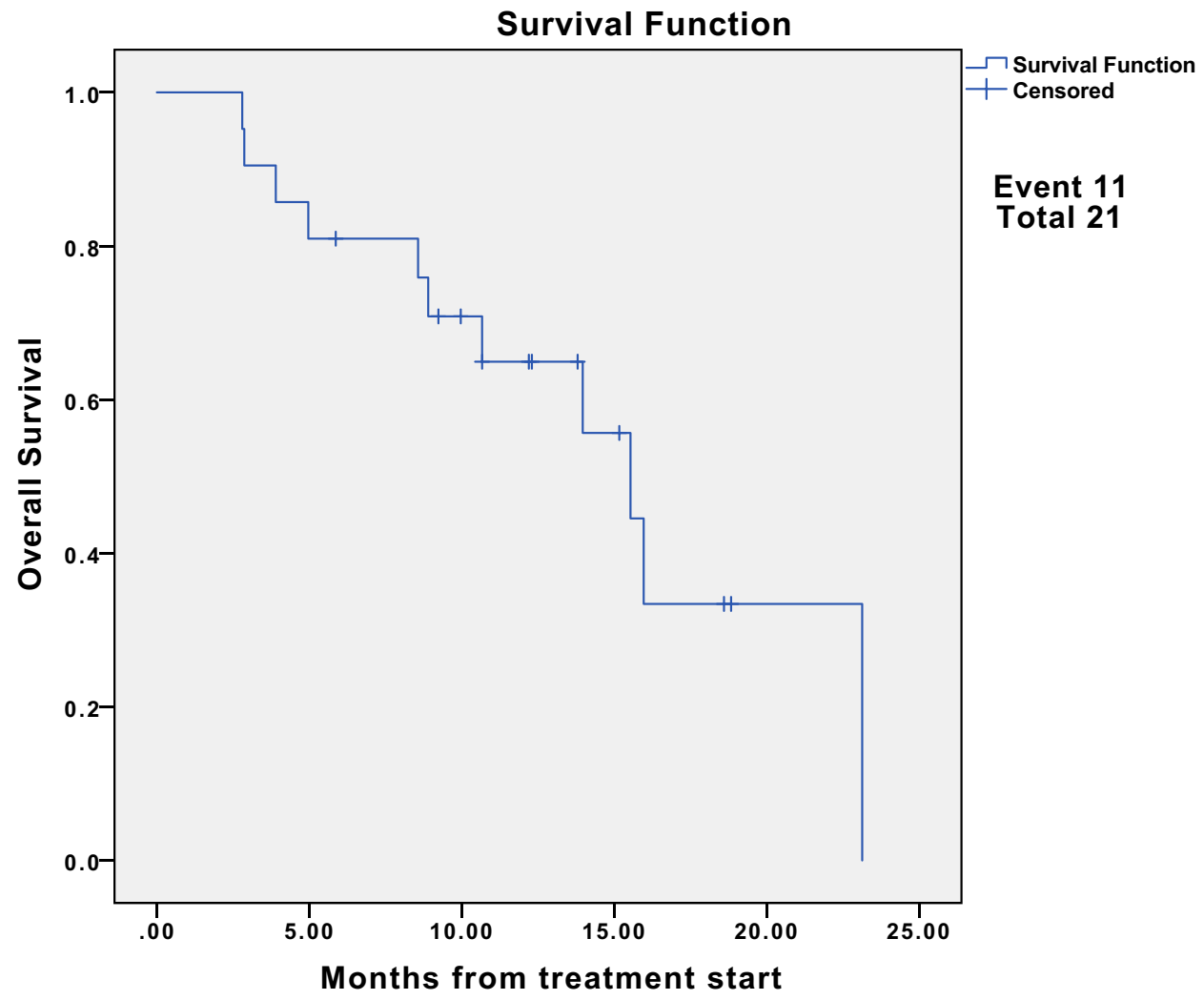

Figure 2 Kaplan-Meier estimates of progression-free survival for all patients. 


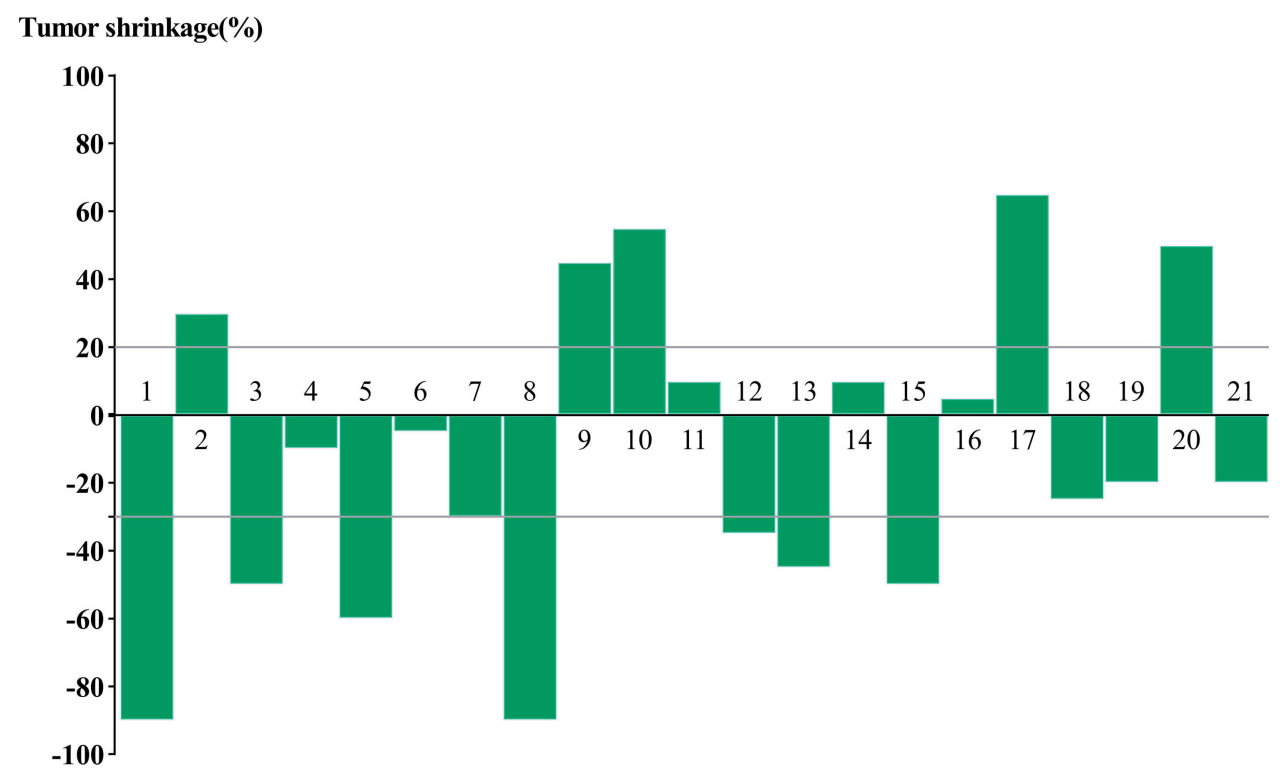

Figure 3 Kaplan-Meier estimates of overall survival for all patients.

the patients treated by placebo. However, pazopanib and regorafenib did not improve the median OS in the trials. $^{15,17}$ And, these drugs were not accessible to the Chinese investigators before January 2019.

Angiogenesis plays a crucial role in tumor growth, invasion, and development of metastasis. ${ }^{33}$ Apatinib is an orally small-molecule VEGFR-TKI, which specifically and strongly inhibits VEGFR-2, decreasing VEGFmediated endothelial cell migration, proliferation, and tumor microvascular formation. ${ }^{19}$ In preclinical

Table 3 Adverse Events

\begin{tabular}{|l|l|l|l|l|}
\hline & Total N (\%) & \multicolumn{3}{|l|}{ Grade } \\
\hline AE & & I & 2 & $3-4$ \\
Hand-foot skin reaction & 7 & 5 & 2 & 0 \\
Oral ulcers & 7 & 3 & 4 & 0 \\
Vomiting & 6 & 3 & 3 & 0 \\
Anorexia & 5 & 3 & 2 & 0 \\
Hair hypopigmentation & 4 & 2 & 2 & 0 \\
Abdominal distention & 4 & 2 & 2 & 0 \\
Elevated Aminotransferase & 2 & 1 & 1 & 0 \\
Diarrhea & 2 & 1 & 1 & 0 \\
Headache & 2 & 2 & 0 & 0 \\
Pneumothorax & 2 & 0 & 1 & 1 \\
Menstrual Irregularities & 2 & 1 & 1 & 0 \\
Fatigue & 1 & 0 & 1 & 0 \\
Wound-healing problems & $\mathrm{I}$ & 0 & 1 & 0 \\
Proteinuria & $\mathrm{I}$ & $\mathrm{I}$ & 0 & 0 \\
Thrombocytopenia & $\mathrm{I}$ & $\mathrm{I}$ & 0 & 0 \\
Hypertension & $\mathrm{I}$ & $\mathrm{I}$ & 0 & 0 \\
Hematuresis & $\mathrm{I}$ & $\mathrm{I}$ & 0 & 0 \\
\hline
\end{tabular}

experiments, apatinib also impaired VEGF-stimulated proliferation, migration and tube formation by human umbilical vein endothelial cells, and blocked rat aortic ring budding in vitro, which may be associated with suppression of VEGFR-2-mediated phosphorylation of Ret, c-Kit, and c-src. ${ }^{34}$ And apatinib has shown its anti-cancer effects in a variety type of tumors, ${ }^{19}$ including STS. ${ }^{20,30,31}$

There were few studies focus on the efficacy of apatinib in advanced SS. Xie et a ${ }^{30}$ reported as a second-line or further-line option, apatinib was administrated for six patients with advanced SS following anthracycline-based chemo-resistance. The median DOR was 5.2 months, and the best response was PR. Chen et $\mathrm{al}^{31}$ reported a case of advanced SS. Apatinib was administrated as a third-line treatment. The PFS and OS were 7.0 and 8.5 months, respectively. And no grade 3 or 4 side effects were observed. However, compared with previous studies, our data show a significant improvement in PFS (13.1 months) and OS (15.5 months), with similar DOR (7.7 months). And, apatinib shows relatively less and lower-grade AEs, when compared to pazopanib and regorafenib. ${ }^{15,17,30}$ Therefore, in our study, most patients received apatinib $750 \mathrm{mg}$ once daily for body surface area (BSA) $>1.5 .^{30}$ The initial dose was relatively high, compared with the previous study. Additionally, although chemotherapy agents primarily act in the cell cycle, SS tumor cells are selected for insensitive chemotherapy, which contributes to the formation of chemotherapy-resistant SS. In the previous study, six advanced SS cases only had a median DOR of 5.2 months with apatinib treatment following 
Table 4 Targeted Agents for Advanced SS

\begin{tabular}{|c|c|c|c|c|c|c|}
\hline Drug (Reference) & $\begin{array}{l}\text { Year of } \\
\text { Publication }\end{array}$ & $\begin{array}{l}\text { No. of } \\
\text { Patients }\end{array}$ & $\begin{array}{l}\text { Prior } \\
\text { Chemotherapy }\end{array}$ & $\begin{array}{l}\text { Target Therapy } \\
\text { Protocol }\end{array}$ & $\begin{array}{l}\text { Best } \\
\text { Response }\end{array}$ & Clinical Outcome \\
\hline $\begin{array}{l}\text { Sorafenib }{ }^{[23]} \\
\text { Pazopanib }\end{array}$ & 2009 & 12 & Yes & $\begin{array}{l}\text { Sorafenib } 400 \mathrm{mg} \text { twice } \\
\text { per day }\end{array}$ & $\begin{array}{l}\text { Six SD } \\
\text { Six PD }\end{array}$ & $\begin{array}{l}\text { Median PFS }=2.5 \mathrm{~m} \\
\text { Median OS }=10.3 \mathrm{~m}\end{array}$ \\
\hline Sleijfer, S. et al ${ }^{[24]}$ & 2009 & 38 & Yes & Pazopanib $800 \mathrm{mg}$ & - & $\begin{array}{l}\text { 3-month PFS } \\
\text { rate }=49 \% \text {, } \\
\text { Median PFS= } 16 \mathrm{Id}\end{array}$ \\
\hline $\begin{array}{l}\text { Van der Graaf, } \\
\text { W. T. et } \mathrm{al}^{[15]}\end{array}$ & 2012 & 44 & Yes & Pazopanib vs Placebo & - & $\begin{array}{l}\text { Median PFS }=4.6 \mathrm{~m}, \\
\text { Median OS }=12.5 \mathrm{~m}\end{array}$ \\
\hline Yoo, K. H. et al ${ }^{[16]}$ & 2015 & 4 & Yes & Pazopanib $800 \mathrm{mg}$ & Two PR & $\begin{array}{l}\text { Median PFS }=7.7 \mathrm{~m} \\
\text { Median } \mathrm{OS}=9.4 \mathrm{~m}\end{array}$ \\
\hline $\begin{array}{l}\text { Nakamura, } \\
\text { T. et al }{ }^{[25]}\end{array}$ & 2016 & 18 & Yes & $\begin{array}{l}\text { Pazopanib 200/400/ } \\
600800 \mathrm{mg}\end{array}$ & $\begin{array}{l}\text { Two PR } \\
\text { Ten SD } \\
\text { Four PD }\end{array}$ & $\begin{array}{l}\text { Median PFS }=16.4 \mathrm{w}, \\
\text { Median OS }=10.6 \mathrm{~m}, \\
6-\text { Month PFS } \\
\text { rate }=42.8 \%, \\
\text { I-Year OS rate }=41.4 \%\end{array}$ \\
\hline $\begin{array}{l}\text { Gelderblom, } \\
\text { H. et al }{ }^{[26]}\end{array}$ & 2017 & 24 & Yes & $\begin{array}{l}\text { Pazopanib 200/400/ } \\
600800 \mathrm{mg}\end{array}$ & $\begin{array}{l}\text { Two PR } \\
\text { Ten SD } \\
\text { Four PD }\end{array}$ & $\begin{array}{l}\text { Median treatment } \\
\text { Duration }=5.1 \mathrm{~m}\end{array}$ \\
\hline $\begin{array}{l}\text { Jee Hung Kim } \\
\text { et al }{ }^{[27]} \\
\text { Regorafenib }\end{array}$ & 2019 & 3 & Yes & $\begin{array}{l}\text { Pazopanib vs Gemcitabine/ } \\
\text { Docetaxel }\end{array}$ & $\begin{array}{l}\text { One PR } \\
\text { One SD } \\
\text { One PD }\end{array}$ & Median PFS=3. $1 \mathrm{~m}$ \\
\hline $\begin{array}{l}\text { Brodowicz, } \\
\text { T. et } \mathrm{al}^{[28]}\end{array}$ & 2015 & 26 & Yes & & One PR & 22 \\
\hline Mir, O. et al ${ }^{[17]}$ & 2016 & 13 & Yes & Regorafenib vs Placebo & $\begin{array}{l}\text { One PR } \\
\text { Ten SD } \\
\text { Two PD }\end{array}$ & $\begin{array}{l}\text { Median PFS }=5.6 \mathrm{~m}, \\
\text { Median OS }=13.4 \mathrm{~m} \text {, } \\
6-\text { Month PFS } \\
\text { rate }=38 \% \text {, } \\
\text { 6-Month OS rate }=77 \%\end{array}$ \\
\hline Berry, V. et al ${ }^{[3]}$ & 2017 & 13 & Yes & Regorafenib vs Placebo & - & $\begin{array}{l}\text { Median PFS=4.0m; } \\
\text { Median } O S=13.4 \mathrm{~m}\end{array}$ \\
\hline $\begin{array}{l}\text { Brodowicz, } \\
\text { T. et al }{ }^{[29]}\end{array}$ & 2018 & 13 & Yes & Regorafenib vs Placebo & $\begin{array}{l}\text { One PR } \\
\text { Ten SD } \\
\text { Two PD }\end{array}$ & $\begin{array}{l}\text { Median PFS=3.8m, } \\
\text { Median OS=13.4m, }\end{array}$ \\
\hline Apatinib & & & & & & \\
\hline Xie et al ${ }^{[30]}$ & 2018 & 6 & Yes & Apatinib $500 \mathrm{mg}$ & PR & Median DOR $=5.2 \mathrm{~m}$ \\
\hline Chen et $\mathrm{a}^{[3 \mathrm{l}]}$ & 2019 & 1 & Yes & Apatinib $500 \mathrm{mg}$ & SD & $\mathrm{PFS}=7 \mathrm{~m}, \mathrm{OS}=8.5 \mathrm{~m}$ \\
\hline Current study & - & 21 & Yes & Apatinib $750 \mathrm{mg}$ & PR & $\begin{array}{l}\text { Median PFS }=13.1 \mathrm{~m}, \\
\text { Median OS=15.5m, }\end{array}$ \\
\hline
\end{tabular}

Abbreviations: CR, complete response; PR, partial response; SD, stable disease; PD, progressive disease; NA, not achieved; ORR, objective response rate (including the percentage of $C R$ and $P R$ ); PFS, progression-free survival; OS, overall survival; OSR, overall survival rate.

poor response to at least two circles of anthracycline-based chemotherapy. ${ }^{30}$ However, van der Graaf et al ${ }^{15}$ reported pazopanib improved the median PFS (5.6 months) and OS (13.4 months) in advanced SS patients who previously had one circle chemotherapy. So apatinib was administered after the poor response of one circle chemotherapy in our study, with the notable result of nine PR and eight SD (Figure 4). Therefore, we speculate the improvement of median OS, especially PFS, is extensively influenced by the relatively high dose and advanced treatment, when compared to early trials. ${ }^{15,17,30}$

For the AEs, previous studies reported the most common toxicities were hand-foot skin reaction, fatigue, rash or desquamation, and hypertension for advanced STS. ${ }^{20,30}$ In our cases, the most common AEs in our study were hand-foot skin reaction $(7 / 21[33.3 \%])$, oral ulcers $(7 / 21$ 


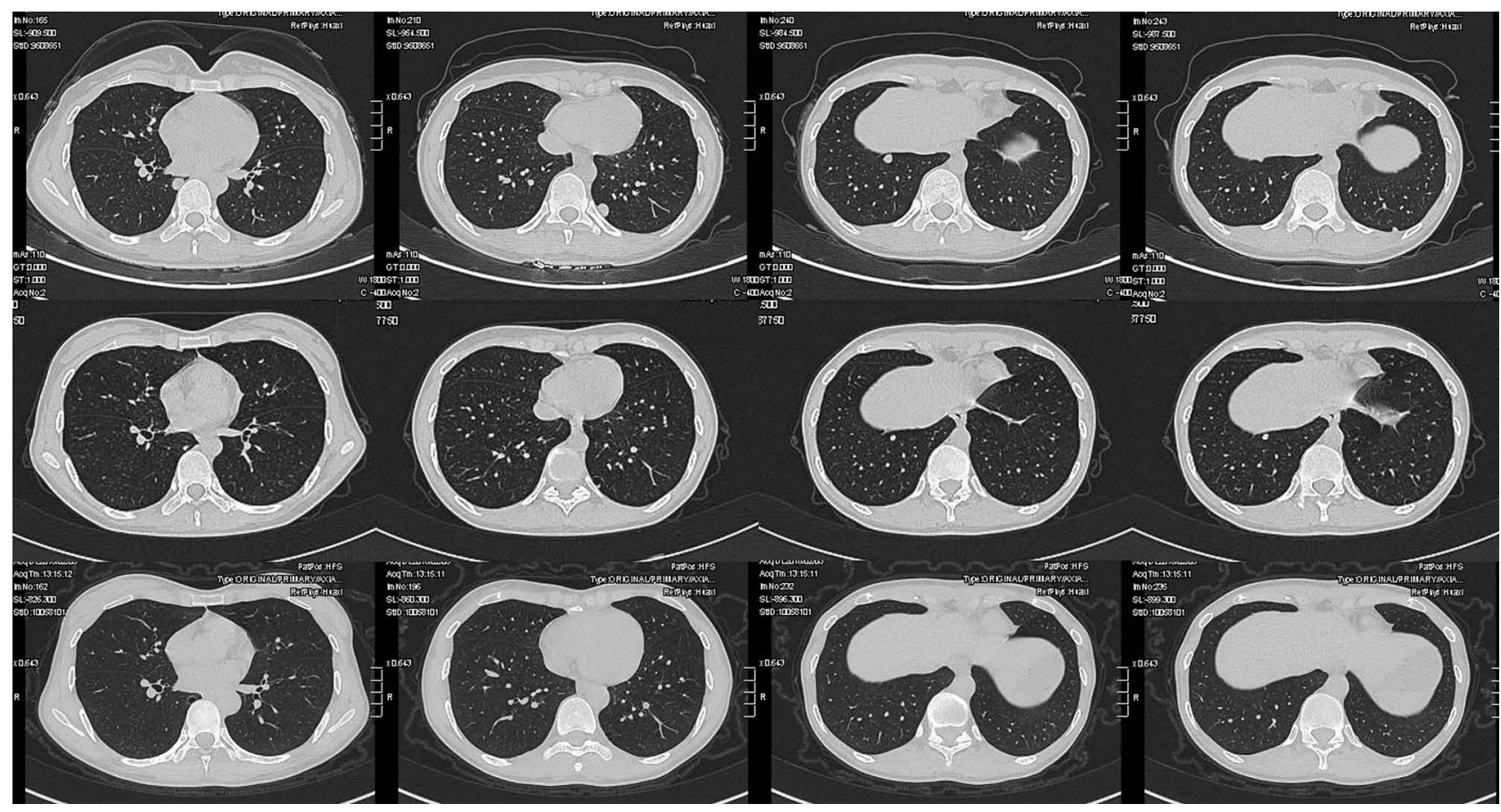

Figure 4 The patient with partial response showing response to the treatment with apatinib.

[33.3\%]), and vomiting (6/21[28.6\%]). Then, only one patient had to discontinue apatinib because of hand-foot skin reaction, and one patient received closed chest drainage following grade 4 pneumothorax. No other grade $3 / 4$ toxicities were detected. However, as mainstream care for patients with non-adipocytic sarcomas, the use of pazopanib had induced several grade $\geq 3$ toxicities including neutropenia, thrombocytopenia, pulmonary embolism, and nausea. ${ }^{26,27}$ Rapid and fatal acute heart failure had been even reported which induced by pazopanib. ${ }^{35}$ The quality of life was significantly decreased in SS patients who administrated pazopanib because of AEs (ie, diarrhea, anorexia, nausea, vomiting, and asthenia). ${ }^{15}$ Meanwhile, three of all the 14 patients discontinued regorafenib for the regorafenib-induced toxicities. ${ }^{17}$ Hypertension, hand-foot skin reaction, and asthenia were the most common grade $\geq 3$ toxicities for STS patients with regorafenib. ${ }^{17}$ However, the overall toxicity and safety of apatinib were relatively better in advanced SS patients, when compared to pazopanib and regorafenib.

The study has several limitations. Firstly, it was a retrospective review of one institution, and there was no control for comparison. Secondly, we only enrolled 21 patients with a median follow-up time of 15.2 months. Moreover, regardless of the encouraging results, our study is lacking the relevant research on the mechanism of molecular biology in each patient. When making histological diagnose, our institution just concluded the typical immunohistochemical features of SS including: CD99 (+), vimentin (+), WT-1 (+), CK (-), HBME1 (-), TTF1 (-), Napsin A (-), p16 (-), NSE (-), Chromogranin A (-), Bcl-2 $(+)$. However, our results are highly variable, whether the immunohistochemical features will impact on the clinical outcomes is unknown. Moreover, apatinib is known as a VEGFR-TKI, but the definite mechanism of antitumor activity remains a question. Therefore, prospective studies with multicenter and large sample are needed for further evaluating the efficacy and safety of apatinib.

\section{Conclusions}

In our study, the advanced SS patients with poor response to anthracycline-based chemotherapy revealed favorable shortterm outcomes after using apatinib. Although the evidence level of this study seems preliminary, patients treated with apatinib indeed had a significant improvement on OS, and particularly on PFS. Meanwhile, the apatinib-induced toxicities were tolerable for most advanced SS patients. Apatinib was proved to be a potential second-line treatment option for advanced SS patients with chemo-resistance. Certainly, further long-term randomized controlled multicenter study with larger cases will fully determine the clinical application of apatinib in advanced SS. 


\section{Acknowledgments}

We are thankful for the support of the nurse team from the Department of Orthopedics, West China Hospital. We are thankful for the patients enrolled in this study. The abstract of this paper was presented at the 40th SICOT Orthopaedic World Congress as an oral presentation talk with interim findings.

\section{Funding}

This work was supported, in part, by the National Natural Science Foundation of China (No. 81702664 and 81801852), and National Key Research and Development Program of China (No. 2017YFB0702604).

\section{Disclosure}

The authors report no conflicts of interest in this work.

\section{References}

1. Baldi GG, Orbach D, Bertulli R, et al. Standard treatment and emerging drugs for managing synovial sarcoma: adult's and pediatric oncologist perspective. Expert Opin Emerg Drugs. 2019;24 (1):43-53. doi:10.1080/14728214.2019.1591367

2. Riedel RF, Jones RL, Italiano A, et al. Systemic anti-cancer therapy in synovial sarcoma: a systematic review. Cancers. 2018;10:11. doi:10.3390/cancers 10110417

3. Berry V, Basson L, Bogart E, et al. REGOSARC: regorafenib versus placebo in doxorubicin-refractory soft-tissue sarcoma-A quality-adjusted time without symptoms of progression or toxicity analysis. Cancer. 2017;123(12):2294-2302. doi:10.1002/cncr.30 661

4. Ladanyi M. Fusions of the SYT and SSX genes in synovial sarcoma. Oncogene. 2001;20(40):5755-5762. doi:10.1038/sj.onc.1204601

5. Wang S, Song R, Sun T, et al. Survival changes in patients with Synovial Sarcoma, 19832012. J Cancer. 2017;8(10):1759-1768. doi:10.7150/jca. 17349

6. Palmerini E, Staals EL, Alberghini M, et al. Synovial sarcoma: retrospective analysis of 250 patients treated at a single institution. Cancer. 2009;115(13):2988-2998. doi:10.1002/cncr.24370

7. Ferrari A, De Salvo GL, Brennan B, et al. Synovial sarcoma in children and adolescents: the European pediatric soft tissue sarcoma study group prospective trial (EpSSG NRSTS 2005). Ann Oncol. 2015;26(3):567-572. doi:10.1093/annonc/mdu 562

8. Stacchiotti S, Van Tine BA. Synovial Sarcoma: current concepts and future perspectives. J Clin Oncol. 2018;36(2):180-187. doi:10.1200/ JCO.2017.75.1941

9. Bianchi G, Sambri A, Righi A, Dei Tos AP, Picci P, Donati D. Histology and grading are important prognostic factors in synovial sarcoma. Eur J Surg Oncol. 2017;43(9):1733-1739. doi:10.1016/j. ejso.2017.05.020

10. Ferrari A, Gronchi A, Casanova M, et al. Synovial sarcoma: a retrospective analysis of 271 patients of all ages treated at a single institution. Cancer. 2004;101(3):627-634. doi:10.1002/ cncr. 20386

11. von Mehren M, Randall RL, Benjamin RS, et al. Soft tissue sarcoma, Version 2.2018, NCCN clinical practice guidelines in oncology. $J$ Natl Compr Canc Netw. 2018;16(5):536-563. doi:10.6004/ jnccn.2018.0025
12. Sleijfer S, Ouali M, van Glabbeke M, et al. Prognostic and predictive factors for outcome to first-line ifosfamide-containing chemotherapy for adult patients with advanced soft tissue sarcomas: an exploratory, retrospective analysis on large series from the European Organization for Research and Treatment of Cancer-Soft Tissue and Bone Sarcoma Group (EORTC-STBSG). Eur J Cancer. 2010;46(1):72-83. doi:10.1016/j.ejca.2009.09.022

13. Tap WD, Papai Z, Van Tine BA, et al. Doxorubicin plus evofosfamide versus doxorubicin alone in locally advanced, unresectable or metastatic soft-tissue sarcoma (TH CR-406/SARC021): an international, multicentre, open-label, randomised Phase 3 trial. Lancet Oncol. 2017;18(8):1089-1103. doi:10.1016/S1470-2045(17)30381-9

14. Kawai A, Araki N, Sugiura H, et al. Trabectedin monotherapy after standard chemotherapy versus best supportive care in patients with advanced, translocation-related sarcoma: a randomised, open-label, Phase 2 study. Lancet Oncol. 2015;16(4):406-416. doi:10.1016/ S1470-2045(15)70098-7

15. van der Graaf WT, Blay JY, Chawla SP, et al. Pazopanib for metastatic soft-tissue sarcoma (PALETTE): a randomised, double-blind, placebo-controlled phase 3 trial. Lancet. 2012;379(9829):1879-1886. doi:10.1016/S0140-6736(12)60651-5

16. Yoo KH, Kim HS, Lee SJ, et al. Efficacy of pazopanib monotherapy in patients who had been heavily pretreated for metastatic soft tissue sarcoma: a retrospective case series. BMC Cancer. 2015;15:154. doi:10.1186/s12885-015-1160-x

17. Mir O, Brodowicz T, Italiano A, et al. Safety and efficacy of regorafenib in patients with advanced soft tissue sarcoma (REGOSARC): a randomised, double-blind, placebo-controlled, phase 2 trial. Lancet Oncol. 2016;17(12):1732-1742. doi:10.1016/S1470-2045(16)30507-1

18. Mi YJ, Liang YJ, Huang HB, et al. Apatinib (YN968D1) reverses multidrug resistance by inhibiting the efflux function of multiple ATP-binding cassette transporters. Cancer Res. 2010;70(20):79 81-7991. doi:10.1158/0008-5472.CAN-10-0111

19. $\mathrm{Li} \mathrm{J}, \mathrm{Qin} \mathrm{S}, \mathrm{Xu} \mathrm{J}$, et al. Randomized, double-blind, placebo-controlled phase iii trial of apatinib in patients with chemotherapy-refractory advanced or metastatic adenocarcinoma of the stomach or gastroesophageal junction. J Clin Oncol. 2016;34 (13):1448-1454. doi:10.1200/JCO.2015.63.5995

20. Zhu B, Li J, Xie Q, Diao L, Gai L, Yang W. Efficacy and safety of apatinib monotherapy in advanced bone and soft tissue sarcoma: an observational study. Cancer Biol Ther. 2018;19(3):198-204. doi:10.1080/15384047.2017.1416275

21. Eisenhauer EA, Therasse P, Bogaerts J, et al. New response evaluation criteria in solid tumours: revised RECIST guideline (version 1.1). Eur $J$ Cancer. 2009;45(2):228-247. doi:10.1016/j.ejca.2008.10.026

22. von Mehren M, Randall RL, Benjamin RS, et al. Soft tissue sarcoma, Version 2.2016, NCCN clinical practice guidelines in oncology. J Natl Compr Canc Netw. 2016;14(6):758-786. doi:10.6004/jnccn.2016.0078

23. Maki RG, D'Adamo DR, Keohan ML, et al. Phase II study of sorafenib in patients with metastatic or recurrent sarcomas. J Clin Oncol. 2009;27(19):3133-3140. doi:10.1200/JCO.2008.20.4495

24. Sleijfer S, Ray-Coquard I, Papai Z, et al. Pazopanib, a multikinase angiogenesis inhibitor, in patients with relapsed or refractory advanced soft tissue sarcoma: a phase II study from the European organisation for research and treatment of cancer-soft tissue and bone sarcoma group (EORTC study 62043). J Clin Oncol. 2009;27 (19):3126-3132. doi:10.1200/JCO.2008.21.3223

25. Nakamura T, Matsumine A, Kawai A, et al. The clinical outcome of pazopanib treatment in Japanese patients with relapsed soft tissue sarcoma: A Japanese Musculoskeletal Oncology Group (JMOG) study. Cancer. 2016;122(9):1408-1416. doi:10.1002/cncr.29961

26. Gelderblom H, Judson IR, Benson C, et al. Treatment patterns and clinical outcomes with pazopanib in patients with advanced soft tissue sarcomas in a compassionate use setting: results of the SPIRE study(). Acta Oncol. 2017;56(12):1769-1775. doi:10.1080/ 0284186X.2017.1332779 
27. Kim JH, Park HS, Heo SJ, et al. Differences in the efficacies of pazopanib and gemcitabine/docetaxel as second-line treatments for metastatic soft tissue Sarcoma. Oncology. 2019;96(2):59-69. doi: $10.1159 / 000492597$

28. Brodowicz T, Liegl-Atzwager B, Tresch E, et al. Study protocol of REGOSARC trial: activity and safety of regorafenib in advanced soft tissue sarcoma: a multinational, randomized, placebo-controlled, phase II trial. BMC Cancer. 2015;15:127. doi:10.1186/s12885-015-1143-y

29. Brodowicz T, Mir O, Wallet J, et al. Efficacy and safety of regorafenib compared to placebo and to post-cross-over regorafenib in advanced non-adipocytic soft tissue sarcoma. Eur J Cancer. 2018;99:28-36. doi:10.1016/j.ejca.2018.05.008

30. Xie L, Guo W, Wang Y, Yan T, Ji T, Xu J. Apatinib for advanced sarcoma: results from multiple institutions' off-label use in China. BMC Cancer. 2018;18(1):396. doi:10.1186/s12885-018-4303-Z

31. Chen S, Zhang K, Wan X, Chen Y, Ma S, Deng Q. The use of apatinib in treating primary pleural synovial sarcoma: A case report. Medicine. 2019;98(51):e18382. doi:10.1097/MD.0000000000018382
32. Agulnik M, Attia S. Growing role of regorafenib in the treatment of patients with Sarcoma. Target Oncol. 2018;13(4):417-422. doi:10.10 07/s11523-018-0575-0

33. Ranieri G, Gadaleta CD, Patruno R, et al. A model of study for human cancer: spontaneous occurring tumors in dogs. Biological features and translation for new anticancer therapies. Crit Rev Oncol Hematol. 2013;88(1):187-197. doi:10.1016/j.critrevonc.2013. 03.005

34. Tian S, Quan H, Xie C, et al. YN968D1 is a novel and selective inhibitor of vascular endothelial growth factor receptor-2 tyrosine kinase with potent activity in vitro and in vivo. Cancer Sci. 2011;102(7):1374-1380. doi:10.1111/j.1349-7006.2011.019 39.x

35. van Marcke C, Ledoux B, Petit B, Seront E. Rapid and fatal acute heart failure induced by pazopanib. BMJ Case Rep. 2015;2015.

\section{Publish your work in this journal}

Cancer Management and Research is an international, peer-reviewed open access journal focusing on cancer research and the optimal use of preventative and integrated treatment interventions to achieve improved outcomes, enhanced survival and quality of life for the cancer patient.
The manuscript management system is completely online and includes a very quick and fair peer-review system, which is all easy to use. Visit http://www.dovepress.com/testimonials.php to read real quotes from published authors. 